\title{
Evaluating the Importance of Personal Information Attributes using Graph Mining Technique
}

\author{
Ake Osothongs \\ School of Multidisciplinary, \\ Department of Informatics, \\ The Graduate University for \\ Advanced Studies [Sokendai] \\ 2-1-2 Hitotsubashi, Chiyoda-ku \\ Tokyo, Japan \\ ake@nii.ac.jp
}

\author{
Vorapong Suppakitpaisan \\ Global Research Center for \\ Big Data Mathematics, \\ National Institute of Informatics; \\ JST, ERATO Kawarabayashi \\ Large Graph Project \\ 2-1-2 Hitotsubashi, Chiyoda-ku \\ Tokyo, Japan \\ vorapong@nii.ac.jp
}

\author{
Noboru Sonehara \\ Information and Society \\ Research Division, \\ National Institute of Informatics \\ School of Multidisciplinary, \\ Department of Informatics, \\ The Graduate University for \\ Advanced Studies [Sokendai] \\ 2-1-2 Hitotsubashi, Chiyoda-ku \\ Tokyo, Japan \\ sonehara@nii.ac.jp
}

\begin{abstract}
Personal information is used as a medium for service co-creation between consumer and service provider. The service provider now views personal information as a type of asset and tries to collects it as much as possible, whereas the consumer does not want to disclose it. The service provider has to find a strategy to collect personal information legally, maybe by providing a platform for trade-off between personal information and monetary rewards. There are several methods proposed to estimate the worth of personal information for the trade-off, but none of them studies the value of each specific attribute. Our survey shows that the value of each attribute varies from the users' point of view, as most regard an attribute such as National ID is more valuable than those of age or gender. We proposed here a technique to measure and compare the importance of each personal information attribute. Using the results from our survey, we constructed a network based on Bayes' formula. Then, we used a graph mining technique to find a relationship between the attributes. The results obtained from the graph mining technique indicate an interesting hierarchical relationship between the attributes. Hierarchy can be used for evaluating each attribute in the trading platform. Also, the results can be used for improving the effectiveness of privacy protection schemes, such as $k$-anonymity.
\end{abstract}

\section{Categories and Subject Descriptors}

H.2.8 [Database Management]: Database Applications - Data mining, K.4.1 [Computers and Society]: Public Policy Issuesprivacy

\section{General Terms}

Measurement, Security.

(c) 2014 Association for Computing Machinery. ACM acknowledges that this contribution was authored or co-authored by an employee, contractor or affiliate of a national government. As such, the Government retains a nonexclusive, royalty-free right to publish or reproduce this article, or to allow others to do so, for Government purposes only.

IMCOM '15, January 08 - 10 2015, BALI, Indonesia Copyright 2015 ACM 978-1-4503-3377-1/15/01 ...\$15.00 http://dx.doi.org/10.1145/2701126.2701200

\section{Keywords}

Personal information management, privacy, personal information measurement, data mining

\section{INTRODUCTION}

The collection of personal information is a common activity in the Big Data age. People leave their personal information as a trace on every online activity. Personal information is produced from every device that can connect to the Internet, such as personal computers, mobile phones, and tablets. Today, service providers collect personal information for many purposes. For example, private companies who run an e-commerce website collect personal information in order to improve target advertising and personalized marketing. Academics use personal information for research activities and health care institutes collect personal information for research and diagnosis.

Moreover, personal information has now become a kind of asset, which can be traded or sold to third parties. Every day, data brokers collect, analyze and pack consumer's personal information for sale or transfer as a commodity [1], [2]. They sell it to third parties, such as private companies, research institutes and government agencies without notice to the person who created it. For this reason privacy issues are sometimes raised because the information may be sensitive and personal. The more data a service provider collects, then the higher the risk of invasion of privacy.

In addition, people nowadays have a higher concern and awareness of their privacy [3]. Some countries have published legal documents and regulations to protect the personal information and privacy of their citizens. Service providers are required to gain consumer consent from each individual before use, buy, sell or barter their personal information [4]. There are several ideas to provide a method for trade-off between personal information and monetary reward such as personal information trading platform [5], which operate between the service provider and consumer. The platform aims to be a medium for consumers who wish to disclose their personal information in exchange for monetary reward from the service providers. A challenging problem in creating this platform is the estimation of the monetary reward that the service provider has to pay to the consumer. Although personal information 
is a type of asset, it is difficult to measure as a value for trading. It is difficult to negotiate like other tangible commodities and problematic to estimate as a price for each information unit. When service providers, such as websites or mobile applications require consumers to disclose their information, they usually comply without any negotiation.

\subsection{Our Contributions}

A lot of research has been done to estimate the value of personal information, but the results varied [6], [7], [8]. However, the goal of these papers was to find a cost per person. Many researchers assumed that all attributes had the same cost [9], [10].

Our survey indicated that this assumption might not be correct. Most of the 532 subjects that participated in the survey indicated that they may reveal their office email, gender, or age if it is required to use a service provided. However, only a small fraction of them were willing to disclose their national ID.

That result motivated us to find the relationship between the importance between attributes from the users' point of view. We proposed a technique based on graph mining to measure the importance of each personal attribute. Using the result from our survey, we constructed a network based on Bayes' formula. Then, we used a graph clustering technique to group these attributes into clusters. We found that our network is well-clustered into groups with some semantic similarity between the attributes in each group. Also, we found a hierarchical structure in our network. The top of our hierarchical structure contains important attributes such as national ID; the leaf of the structure contains less important information such as office email, age, and gender. Our hierarchical structure can help the trading system to calculate the value of each attribute precisely. The attribute at the top will have a higher value than the attribute at the bottom.

This paper is organized as follows. In Section 2, we examined the definition of personal information that will be used in this study. In Section 3, we discussed the problems of personal information measurement which we focused on in this research. In section 4, we discussed related works and other methods used to estimate the value of personal information. In section 5, we detailed the research methods, the data collection, calculation and graph mining. We calculated a priority of personal information, created a graph of personal information disclosure and found the community of the graph. In section 6, we presented the results of personal information disclosure and analyzed the graph result. In the last section, we concluded the study result and discussed the advantages of this method that can be used as a new method to increase the disclosure of personal information and also be useful in other applications.

\section{PRELIMINARY DEFINITION}

The definition of personal information (PI) changes from time to time because it reflects the development of information technology. The terms 'personal data' and 'personal identifiable information (PII)' are usually found and used in the same context as 'personal information'. In the 1900 s and early 21 st century when most databases were not yet online and still individual systems, personal information usually referred to information which could identify a single person directly or indirectly [11], [12].

However, the meaning of personal information has changed in this Big Data era, whereby every system is connected together and also connected to the Internet. The Big Data makes the judge more complicated. People produce a great deal of information online, which all can be traced back to individuals. Researchers have frequently found that a small piece of unimportant information can be re-identified identify one particular person [13], [14].

In this study, personal information is defined as information that directly or indirectly relates to a person, regardless of its source.

\section{RESEARCH PROBLEM}

Even though personal information collection has become common procedure in this Big Data age when we use online services, consumers still lack the ability to control their personal information [15]. Consumers have to trade-off their privacy for products or services when the service providers request personal information more than necessary [16]. Authors have suggested ideas that provide methods to control the trade-off of personal information for example personal information negotiation platforms [5]. Service providers generally attract consumers to disclose their personal information by using the monetary rewards such as money as this can increase willingness to disclose personal information and decrease false information [17], [18]. However, personal information is difficult to trade for monetary rewards because there is no measurement method. Which personal information attribute has a higher value than another? This question is difficult to solve. Researchers have tried to estimate the cost of personal information for trade or bargain using many methods.

We may look at the character of personal information and compare it with other commodities such as gold, oil and rice. We can see that other commodities are easy to measure using many unit types and each unit can be converted into cost. Moreover, most of the commodities have their own central markets, where the market price is set which allows brokers to trade or bargain easily. The cost of personal information is difficult to estimate because it is an intangible asset. Each consumer has his or her own individual estimate cost and there is no market place for price comparison. The problem becomes more complex when we want to trade-off personal information in an automated system such as automated negotiation system. How can the system understand the value of each personal information attribute and negotiate without using a cost estimation?

In this study, the problem is focused on personal information measurement and how to use it for supporting trade-off and negotiation processes in the future.

\section{RELATED WORKS}

To compare personal information attributes, we need a method to estimate their value. Most researches estimated personal information by using cost estimation for personal information.

Researchers are trying to find the hidden value and worth of personal information. Personal information has its own value that service providers are ready to pay for, but this quantity is still difficult to estimate. Many data brokers now sell personal information to third party buyers for low value. For example, the Financial Times calculated a personal data worth based on the analysis of industry's pricing data in the US. They found that most consumers have overall personal information worth less than one dollar [19].

On the other hand, many researchers have estimated the worth of personal information using several methods. They found that the worth of personal information is higher than the data broker's cost. 'Cloudsweeper' was developed by researchers in order to find the worth of an email account. The total value was calculated from the cost of other service account values associated with the consumer's 
email. The cost of each service accounts was calculated using quoted prices from a seller in the underground market. The example costs for service accounts in email are $\$ 8$ for iTunes account and $\$ 5$ for Groupon account [6]. Another study in Europe recruited 60 people to take part in the study. They took part in an activity to auction their data from their smart phones every week. The result of the median bid was $€ 2$ across all data categories [7]. In contrast, consumers may also expect the value of their personal information to have a high value. A research showed that a consumer's expected value of his or her personal information, shared on social media was between $\$ 62.79$ to $\$ 106.40$ [8].

Researchers have found that the voluntary disclosure of personal information can be increased when the service provider offers monetary rewards. However, people currently disclose personal information without an actual applicable value. Sometimes, they disclose personal information for a high value of service, yet sometimes they trade it for nothing. This fact shows how difficult it is to estimate the worth of personal information. It is a paradox problem.

In recent years, as a consequence of data mining applications and other exploration purposes, we wish to share our personal data, information while still preserving the privacy of the consumer, several methods have been introduced in the literature. Those include $k$-anonymity [20], $\ell$-diversity [21], and $t$-closeness [22]. To keep the data privacy, these schemes hide some specific personal information, and there are many works trying to minimize those hidden personal information [9], [10]. In those researches, all personal information attributes are equally considered, hiding an important attribute such as national ID is considered to be similar to hiding less important attributes such as gender or age. We show here that this assumption might not be true from the users' point of view. We hope that the people in this research field can use our result to derive a privacy protection method based on the importance of attribute found in this paper. which is usually encoded as tabular information. To reveal tabular

\section{RESEARCH METHODS}

\subsection{Data Collection}

In late 2013 we gathered the personal information attributes from 212 popular websites. The number of personal information attributes was 33, and the list of the attributes can be found in Table 2. Then, we created a set of survey questions that contained two parts. 1) Demographical information. 2) Likert scale five-level questions that asked for the comfort level when consumers disclosed their personal information attributes. The highest level when people are not comfortable to disclose personal information is 5. The lowest level when people feel comfortable to disclose personal information is 1 . We asked the participants to answer all the fields in the survey. There were 532 people who completed this survey. Their demographic details are shown in Table 1.

Table 1. The demographic details of subjects who participated in our survey

$\begin{array}{llc}\text { Attributes } & \text { Value } & \text { Percentage } \\ \text { Gender } & \text { Male } & 48.4 \% \\ & \text { Female } & 52.1 \% \\ \text { Education } & \text { High School } & 5.4 \% \\ & \text { College } & 2.8 \% \\ & \text { Bachelor's Degree } & 47.6 \% \\ \text { Age } & \text { Graduate School } & 40.5 \% \\ & 15-20 & 3.7 \% \\ & 21-30 & 39.3 \% \\ \text { Occupation } & 31-40 & 47.8 \% \\ & 41-60 & 8.6 \% \\ & \text { Over } 60 & 0.03 \% \\ & \text { Student } & 16.6 \% \\ & \text { Self-employed } & 14.0 \% \\ & \text { Private company } & 32.0 \% \\ & \text { Government Officer } & 27.2 \% \\ & \text { State Enterprise } & 2.8 \% \\ & \text { Unemployed/Housemaid } & 3.5 \% \\ & \text { Other } & 3.5 \%\end{array}$
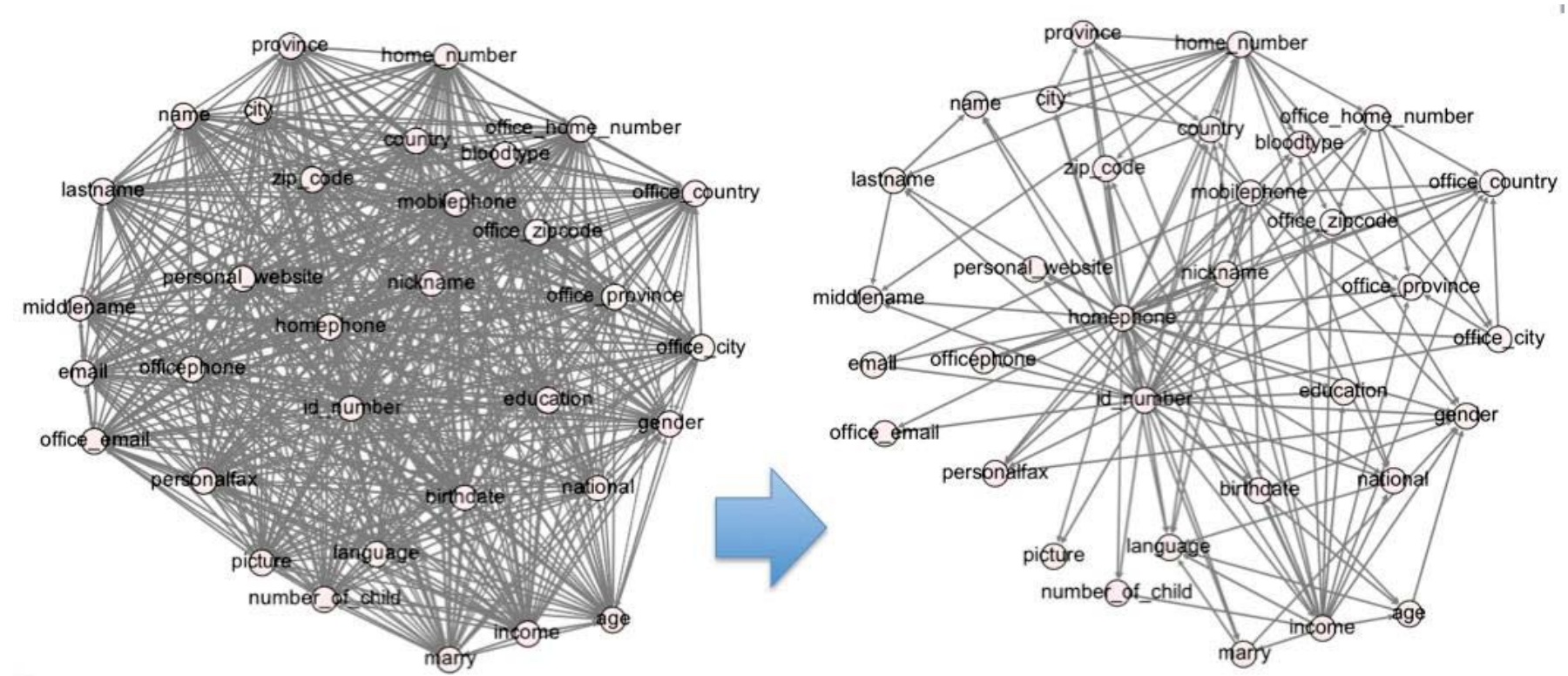

Figure 1. Directed Graph displayed the relation for personal information disclosure before and after filtering 


\subsection{Finding Relation between PI Attributes}

In this study we aimed to find the relation of personal information disclosure between each personal information attribute. Once one personal information attribute was disclosed, then how does that affect to the disclosure of other personal information attributes? To find the relationships between attributes a probability method was employed. In this study, a well-known likelihood method, Bayes' formula, was considered. Bayes' formula is an important method for computing conditional probabilities and is used to compute posterior probabilities given observations.

Firstly, we prepared the dataset from the Likert scale five-level questionnaire. Each answer contained the comfort level at which consumers disclose each attribute of their personal information. We normalized the survey result to two conditions that are 'disclose' and 'protect'. When the score is 1,2 or 3, the condition is 'disclose': the consumer discloses personal information. When the score is 4 or 5, the condition is 'protect': the consumer does not disclose personal information.

Secondly, based on Bayes' formula, we calculated the posterior probability when a disclosed posterior personal information attribute was given by another personal information attribute.

Let $b$ be the information attribute given by $a$, the calculation is expressed by

$$
P(b \mid a)=\frac{P(a \cap b)}{P(a)}
$$

where $P(b \mid a)$ is the probalility that the consumer does not disclose attribute $b$ when the consumer does not disclose $a, P(a \cap b)$ is the probalility that the consumer does not disclose both attributes $a$ and $b$, and $P(a)$ is the probalility that the consumer does not disclose attribute $a$. We will calculate $P(a \cap b)$ by the number of subjects who choose not to disclose both $a$ and $b$ divided by the number of subjects in our survey, while $P(a)$ is the number of subjects who choose not to disclose $a$ divided by the number of all subjects.

For example, 337 subjects choose not to disclose their names. Among those 337 subjects, 324 subjects choose not to disclose their home number. By that, $P($ name $)=\frac{337}{532} \approx 0.633$ and $P($ name $\cap$ homenum $) \approx 0.609$. We get

$$
P(\text { homenum } \mid \text { name }) \approx \frac{0.609}{0.633}=0.961,
$$

which means that $96.1 \%$ of subjects who do not disclose their names choose to protect their national ids. Similarly, we know that

$$
P(\text { officenum } \mid \text { nickname })=\frac{104}{113} \approx 0.920,
$$

because 113 subjects choose not to disclose their nicknames and 104 among them choose not to disclose their office numbers.

\footnotetext{
${ }^{1}$ All graphs shown in this paper are visualized using Gephi [24]
}

\subsection{Graph Construction}

After these calculations, we had a set of results, which were pairs of relationships between each personal information attribute. Next, we transformed the dataset into a directed graph to visualize the dependency among personal information attributes. Each node represented a personal information attribute and each edge of the graph represented a relation between two personal information attributes. Every edge contained a weight that calculated using the probability of personal information disclosure between two connected nodes.

When $P(b \mid a)$ is close to 1 , we know that almost all of the subjects who do not to disclose $a$ are not likely to disclose $b$. From there, we can say that most of the participants think that $b$ is more important than $a$. We remove edges from the graph constructed in the previous paragraph based on that idea. Let $\alpha$ be a probability close to 1 , we will remove all edges $(a, b)$ such that $P(b \mid a)<\alpha$. After that removal, we will get a graph with an edge set $E$ such that for all edges from node $a$ to $b$ in $E$, most users will considered attribute $b$ to be more important than attribute $a$. In this paper, we set $\alpha=0.95$, but we got almost the same result when we set $0.9 \leq$ $\alpha \leq 0.99$ in our experiment.

By the calculation in the previous subsection, we know that there is an edge from name to homenum since $P$ (homenum $\mid$ name $) \geq$ 0.95. Meanwhile, an edge from nickname to of ficenum is removed because $P$ (officenum $\mid$ nickname $)<0.95$.

We show the graph before and after the edge removal in Figure $1^{1}$. We can imply from the graph that most users consider national ID, home phone number, and mobile phone numbers more important than most of the remaining attributes, as there are edges from those attributes to almost all other attributes. Attributes such as age, gender, language or nickname are considered less important, as all edges corresponding to those nodes come from other nodes.

A closer look at the graph suggests that the distribution of in-degree and out-degree of all attributes is varied. Personal information attributes play key roles because they have the distribution of outdegree to all personal information attributes but some personal information attributes have only the distribution of in-degree. The graph interaction provides visualization and navigation information so that we can easily understand the relation between personal information disclosure and personal information attributes. In the following subsection, we will use a graph mining technique to get more information from this graph.

\subsection{Community Detection}

We decided to use a community detection technique to determine the community structure of disclosure of personal information using a technique in [23]. This technique aims to maximize the modularity of the clustering result, $Q$, which can be defined as follows.

$$
\mathrm{Q}=\frac{1}{m} \sum_{i, j \in C}\left[w e i g h t_{i, j}-\frac{d_{i} d_{j}}{m}\right]
$$

where $m$ is the number of edges in the network, $C$ is the set of nodes, weight $i, j$ is the calculated probability of the edge $(i, j)$, and $d_{i} d_{j}$ is a multiplication of the degrees of node $i$ and $j$. 
The personal information attributes were clustered and a new result was displayed using different colors in the graph. We used the probability of disclosing personal information which was calculated as the weight for each edge. The result of community detection from the graph is shown in Figure 2.

The modularity was obtained using the method from our graph at 0.26 , which is significantly high considering to fact that the graph from Subsection 5.3 is very sparse. This result indicates that our graph has a community structure. Besides that, in the following section we will show that attributes in each cluster have some symmetric similarity.

\section{RESULT ANALYSIS AND DISCUSSION}

Beside the fact that the clustering result obtained in the previous section has high modularity, the result also has two other interesting properties. We will discuss about those two properties in this section. In Subsection 6.1, we will show that semantically similar attributes are usually classified into the same group. Then, we will use a hierarchical structure of the graph to evaluate the importance of each attribute in Subsection 6.2.

\subsection{Clustering Result}

To test our hypothesis that each cluster contains attributes which are semantically similar, we manually classified 33 personal information attributes into five categories. Each category contains attributes with similar meaning. The list of those categories is as follows:

1) Name: Information related to personal name

2) Home address: Information related to home address

3) Office address: Information related to office address

4) Contact information and Personal identifiable information: Other information that can identify a single person

5) Other personal information such as demographical information

We combined contact information and personal identifiable information together because both types of personal information can identify an individual.

We compared our classification with the clustering result in Table 2 . As seen in the table, they are very similar. $84.84 \%$ of the personal information was correctly classified. The precision and recall was calculated for each category of personal information and the result are shown in the table. It also showed the restricted relationships among the personal information attributes in every category.

From the previous section, we know that most of our subjects will not disclose any others attributes when they choose to protect national ID, home phone number, and mobile phone number. By this section, we also know that there is an association in user decision to protect two attributes in the same semantic group.

The calculation by this method also showed some other interesting results. The classification was accurate but it also showed some hidden relationships in each personal information attribute. For example, 'nickname' which was classified manually as a member of 'name' category was clustered into the category 'contact information and personal identifiable information type'. We had a closer look at nickname's node and found that it had relations with the disclosure of home phone and mobile phone as demonstrated in Figure 3. We can easily interpret the hidden meaning of this cluster that people will only reveal their nickname to a person who is close to them. It shows that the classification decided by the human is sometimes different from how the human acts.

Table 2. Precision and recall of the calculated result

\begin{tabular}{|c|c|c|c|c|}
\hline Categories & $\begin{array}{c}\text { Manually } \\
\text { Classified } \\
\text { Result }\end{array}$ & $\begin{array}{c}\text { Calculated } \\
\text { Result }\end{array}$ & Precision & Recall \\
\hline Name & $\begin{array}{l}\text { First name, } \\
\text { Last name, } \\
\text { Middle } \\
\text { name, } \\
\text { Nick name }\end{array}$ & $\begin{array}{l}\text { First name, } \\
\text { Last name, } \\
\text { Middle } \\
\text { name }\end{array}$ & 1 & 0.75 \\
\hline $\begin{array}{l}\text { Home } \\
\text { address }\end{array}$ & $\begin{array}{l}\text { Home } \\
\text { number, } \\
\text { City, } \\
\text { Province, } \\
\text { Country, } \\
\text { Zip code, }\end{array}$ & $\begin{array}{l}\text { Home } \\
\text { number, } \\
\text { City, } \\
\text { Province, } \\
\text { Country, } \\
\text { Zip code, } \\
\text { Blood } \\
\text { Type, } \\
\text { Mobile } \\
\text { Phone }\end{array}$ & 0.71 & 1 \\
\hline $\begin{array}{l}\text { Office } \\
\text { address }\end{array}$ & $\begin{array}{l}\text { Office's } \\
\text { home } \\
\text { number, } \\
\text { City, } \\
\text { Province, } \\
\text { Country, } \\
\text { Zip code }\end{array}$ & $\begin{array}{l}\text { Office's } \\
\text { home } \\
\text { number, } \\
\text { City, } \\
\text { Province, } \\
\text { Country, } \\
\text { Zip code }\end{array}$ & 1 & 1 \\
\hline $\begin{array}{l}\text { Contact } \\
\text { information } \\
\text { and } \\
\text { personal } \\
\text { identifiable } \\
\text { information }\end{array}$ & $\begin{array}{l}\text { Home } \\
\text { phone, } \\
\text { Mobile } \\
\text { phone, } \\
\text { Office } \\
\text { phone, } \\
\text { Email, } \\
\text { Office } \\
\text { Email, } \\
\text { Personal } \\
\text { website, } \\
\text { Fax } \\
\text { number, } \\
\text { Id number, } \\
\text { Birth date, } \\
\text { Picture }\end{array}$ & $\begin{array}{l}\text { Home } \\
\text { phone, } \\
\text { Office } \\
\text { phone, } \\
\text { Email, } \\
\text { Office } \\
\text { Email, } \\
\text { Personal } \\
\text { website, } \\
\text { Fax } \\
\text { number, } \\
\text { Id number, } \\
\text { Birth date, } \\
\text { Picture, } \\
\text { Nick name, } \\
\text { Education, } \\
\text { Number of } \\
\text { children }\end{array}$ & 0.75 & 0.9 \\
\hline $\begin{array}{l}\text { Other } \\
\text { personal } \\
\text { information }\end{array}$ & $\begin{array}{l}\text { Gender, } \\
\text { National, } \\
\text { Age, } \\
\text { Income, } \\
\text { Language, } \\
\text { Marriage } \\
\text { status, } \\
\text { Education, } \\
\text { Number of } \\
\text { children, } \\
\text { Blood type }\end{array}$ & $\begin{array}{l}\text { Gender, } \\
\text { National, } \\
\text { Age, } \\
\text { Income, } \\
\text { Language, } \\
\text { Marriage } \\
\text { status }\end{array}$ & 1 & 0.67 \\
\hline
\end{tabular}




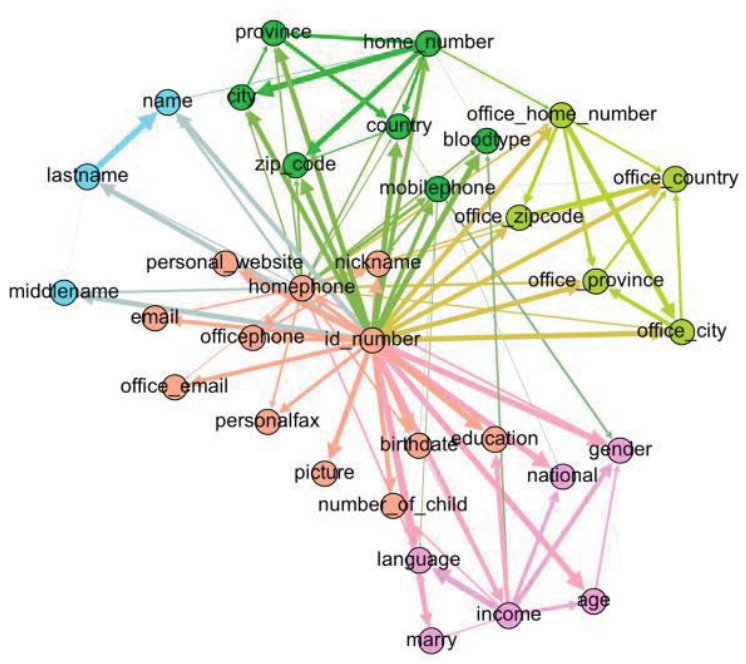

Figure 2. A result graph after clustering

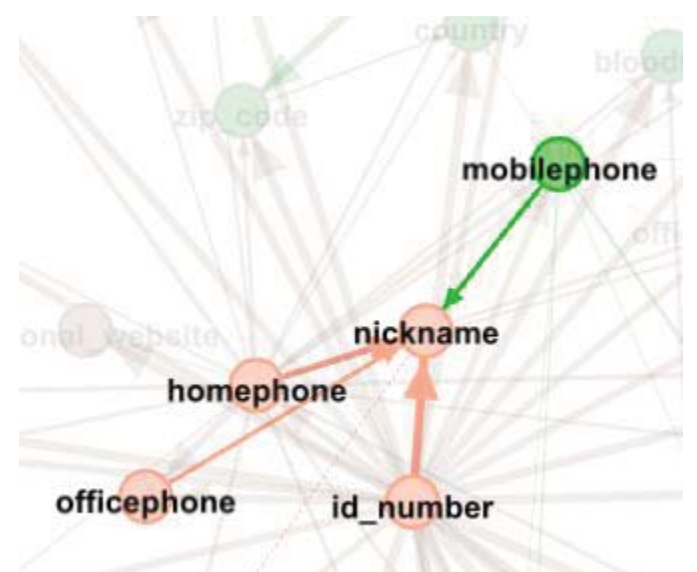

Figure 3. A disclosure hierarchy for nickname

\subsection{PI Measurement by Disclosure Priority}

In Figure 2 we found that once people disclose one personal information attribute they then can disclose more personal information attributes that are less important than the first in hierarchy. Therefore, we can measure the personal information attribute priority by using this result graph. For example, we are now able to compare the result of the priority of ID number with other personal information attributes in Figure 4. ID number has a high priority for the consumer. When people agree to disclose their ID number, then this means that they will disclose all other personal information attributes easily. In Figure 5 we compared the result of the priority of city with other personal information attributes. The node 'city' is directly connected to four other nodes. Among all of them, the node 'province' has a lower priority than the node 'city'. Thus, it can be implied that when people agree to disclose their 'city', they have a high possibility of disclosing 'province' implicitly.

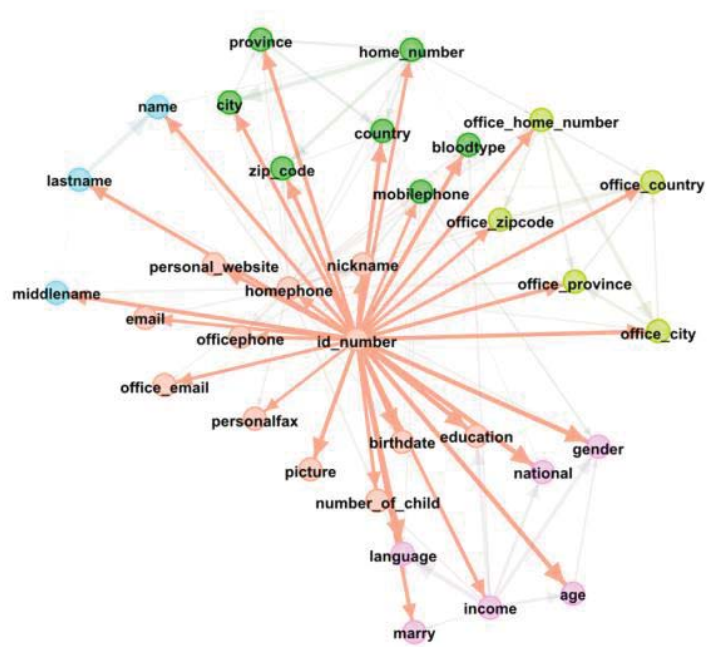

Figure 4. A disclosure hierarchy for ID number

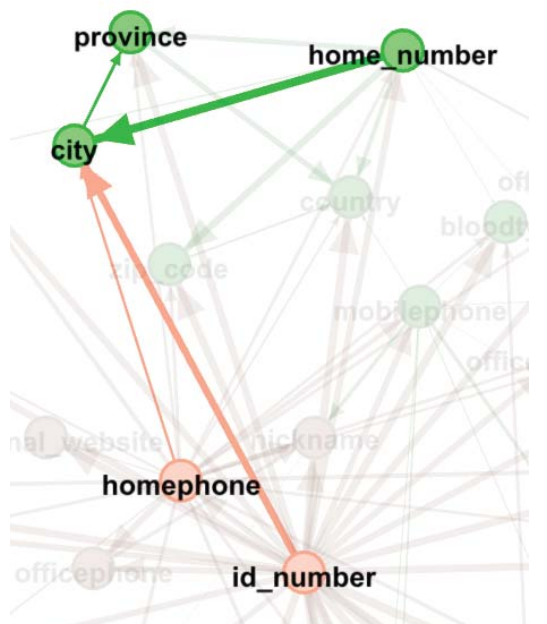

Figure 5. A disclosure hierarchy for city

This method provides an understandable meaning of personal information disclose relationships that can be used for many purposes. For instance, when a service provider creates a trade-off between personal information and monetary rewards they can select a target group, and then select the personal information that they need. If the selected personal information attribute has a higher value for a consumer, then the service provider can request other related personal information attributes that have lower priority. In Figure 4 we may require the high value personal information attribute such as ID number as a mandatory field, then request all other personal information attributes.

Moreover, the measurement result which shown by the graph may be possible to use in other areas such as improving the generalization hierarchies of personal information that usually used in anonymity techniques. 


\section{CONCLUSION}

In real life, the unstructured data and large number of users make the measurement of personal information a lot more complicated. The personal information collection is a complex situation because every piece of information that was created from consumers now can be judged as personal information. For example, social network website do not only collects demographical information, but also collect location, activity log, people's interest, their behavior, click stream, picture, etc. This unstructured information and various types of personal information are difficult to be measured and compared. Which personal information attributes are more important from another attributes? To study the importance of each personal information attributes, in this study, we collected 33 personal information attributed from more than 500 monitors. Our work on this personal information measurement method using a combination of data mining techniques provides meaningful results while the worth of attributes, including price do not necessary have to be estimated. The analysis of the results shows that using our method it is possible to measure personal information value from the relation of personal information disclosure between pairs of personal information attributes. The result graph is easy to understand and gives an advantage to other applications, such as personal information trading system and anonymity improving.

The work provides not only a measurement of personal information, but also a new method to cluster personal information. Thanks to the Big Data era, service providers have more opportunity to collect personal information. However, the number of attributes in many databases such as social network services can be very large for clustering personal information manually. For example, the database in [25] contains several thousand of attributes. Each attribute represents a product sold at a specific website, and the database contains the information if each individual has bought the product. Clearly, we cannot evaluate the importance of those thousand attributes manually. Our method can help the service provider to classify personal information collected from large numbers of consumers. The cluster results show some hidden but meaningful associations of personal information disclosure which service providers may use it for increasing the performance of personal information collection method.

A future challenge of our study will be on the application. This method is easy to calculate and possible to use in many applications. We plan to develop a new privacy policy trading platform. The new platform will be designed to trade between privacy policy from the consumer with monetary reward from the service provider and then use our personal information measurement method in a decision support system for supporting the privacy policy trading and negotiation. Also, we plan to apply our method to a dataset with larger number of attributes. We strongly believe that the result found in this paper can also be obtained in that large dataset.

\section{ACKNOWLEGEMENT}

The authors would like to thank Mr. Rathachai Chawuthai and anonymous reviewers for several useful advices during the course of this research.

\section{REFERENCES}

[1] Kroft, S. 2014. The data brokers: Selling your personal information. Retrieved November 1, 2014, from http://www.cbsnews.com/news/the-data-brokers-sellingyour-personal-information/
[2] Marwick, A. 2014. How Your Data Are Being Deeply Mined, New York Review of Books (January 14, 2014): 22-25.

[3] Shacklett, M., Big data wake-up call: Increased online privacy concerns require risk management. Retrieved November 1, 2014, from

http://www.techrepublic.com/article/big-data-wake-up-callincreased-online-privacy-concerns-require-risk-management/

[4] Office of the Australian Information Commissioner (OAIC), What does 'trading in personal information' mean? Retrieved November 1, 2014, from http://opc.joomlaprime.icemedia.com.au/index.php?option=com_content\&vie $\mathrm{w}=$ article \&id $=721 \&$ Itemid $=1570$

[5] Osothongs, A. and Sonehara, N. 2014. A proposal of personal information trading platform (PIT): A fair trading between personal information and incentives. Conference on Digital Information and Communication Technology and its Applications: 269-274

[6] McCracken, H. 2013. Cloudsweeper's Gmail Security Audit Is Alarming and Useful. Retrieved November 1, 2014, from http://techland.time.com/2013/06/27/gmail-security/

[7] Staiano, J., Oliver N., Lepri B., Oliveira, R., Caraviello, M., and Sebe, N. 2014. Money Walks: A Human-Centric Study on the Economics of Personal Mobile Data. ACM International Joint Conference on Pervasive and Ubiquitous Computing 2014.

[8] Burney,K., Brehm, J. and Robinson, K. Valuing Identity in Today's Digital World: The business case for defining digital identity and how to value it correctly. Retrieved November 1, 2014, from https://www.unboundid.com/company/ news/press/2013/20130730.php

[9] Aggarwal, G., Feder, T., Kenthapadi, K., Motwani, R., Panigrahy, R., Thomas, D., and Zhu, A. 2005. Approximation algorithms for k-anonymity. Journal of Privacy Technology.

[10] Choromanski, K. M., Jebara, T., and Tang, K. 2013. Adaptive Anonymity via $b$-Matching. Advances in Neural Information Processing Systems.

[11] Katrine, E. 2006. Personal Information in New Zealand: Between a Rock and a Hard Place? Interpreting Privacy Principles: Chaos or Consistency? Symposium. Sydney, 1.

[12] Directive 95/46/EC of the European Parliament and of the Council of 24 October 1995 on the protection of individuals with regard to the processing of personal data and on the free movement of such data, Retrieved November 1, 2014, from http://eur-lex.europa.eu/LexUriServ/LexUriServ.do?uri= CELEX:31995L0046:en:HTML, [Apr. 14, 2014]

[13] Tene, O. and Polonetsky, J. 2012. Privacy in the Age of Big Data: A Time for Big Decisions. Stanford Law Review 64. 2012, pp. 63-69.

[14] Arvind, N. and Vitaly, S. 2010. Myths and fallacies of personally identifiable information. Communications of the ACM. 2010, 53.6: 24-26.

[15] Kearney, A.T. Rethinking Personal Data: A New Lens for Strengthening Trust, World Economic Forum. Retrieved November 1, 2014, from http://www3.weforum.org/docs/ WEF_RethinkingPersonalData_ANewLens_Report_2014.pd $\mathrm{f}$ 
[16] Aïmeur, E. and Schonfeld, D. 2011. The ultimate invasion of privacy: Identity theft. Privacy, Security and Trust (PST), 2011 Ninth Annual International Conference. 2011, pp. 2431.

[17] Shibchurn, Joshana, and Xiang Bin Yan. 2014. Investigating Effects of Monetary Reward on Information Disclosure by Online Social Networks Users. System Sciences (HICSS). 2014 47th Hawaii International Conference on. IEEE.

[18] Andrade, E. B. , Kaltcheva, V., and Weitz, B., Selfdisclosure on the Web: the impact of privacy policy, reward, and company reputation. Advances in Consumer Research. No. 29., 2002, pp. 350-353.

[19] Steel, E., Locke, C., Cadman, E., Freese, B. 2013. How much is your personal data worth? Retrieved November 1, 2014, from http://www.ft.com/intl/cms/s/2/927ca86e-d29b-11e288ed-00144feab7de.html\#axzz3CnV10qaO

[20] Sweeney, L. 2002. Achieving k-anonymity privacy protection using generalization and suppression.
International Journal of Uncertainty. Fuzziness and Knowledge-Based Systems. 10.05: 571-588.

[21] Machanavajjhala, A., Kifer, D., Gehrke, J. and Venkitasubramaniam, M. 2007.

1-diversity: Privacy beyond k-anonymity. ACM Transactions on Knowledge Discovery from Data. 1.1 (2007): 3.

[22] Li, N., Li, T., and Venkatasubramanian, S. 2007. tCloseness: Privacy Beyond k-Anonymity and 1-Diversity. ICDE. Vol. 7. 2007.

[23] Blondel, V. D., Guillaume, J. L., Lambiotte, R. and Etienne, L. 2008. Fast unfolding of communities in large networks. Journal of Statistical Mechanics: Theory and Experiment. 2008.10: P1000

[24] Gephi NGO. 2014. Gephi - the open graph viz platform. Retrieved November 6, 2014, from http://gephi.org

[25] Ghinita, G., Tao, Y. and Kalnis, P. 2008. On the anonymization of sparse high-dimensional data. ICDE. Vol. 8. 2008. 